\title{
Citrus phytochemicals and their potential effects on the prevention and treatment of obesity: review and progress of the past 10 years
}

\author{
Shi Feng ${ }^{\mathrm{a}, \mathrm{b}}$ and Yu Wang ${ }^{\mathrm{a}, \mathrm{b}^{*}}$
}

\begin{abstract}
${ }^{a}$ Citrus Research \& Education Center, University of Florida, 700 Experiment Station Rd. Lake Alfred, FL 33850, USA
${ }^{b}$ Food Science and Human Nutrition, University of Florida, 572 Newell Dr. Gainesville, FL 32611, USA

${ }^{*}$ Corresponding author: Yu Wang, Citrus Research \& Education Center, University of Florida, 700 Experiment Station Rd. Lake Alfred, FL 33850, USA. Tel: 863-956-8673; Fax: (863)-956-4631; E-mail: yu.wang@ufl.edu
\end{abstract}

DOI: $10.31665 / J F B .2018 .4165$

Received: December 10, 2018; Revised received \& accepted: December 22, 2018

Citation: Feng, S., and Wang, Y. (2018). Citrus phytochemicals and their potential effects on the prevention and treatment of obesity: review and progress of the past 10 years. J. Food Bioact. 4: 99-106.

\begin{abstract}
Obesity is a chronic life-threatening disease throughout the world. Available anti-obesity drugs may have hazardous side effects and no long-term safety assurance is in place for patients. In recent decades, alternative natural therapeutics have been intensively investigated. Among them, phytochemicals from citrus fruits have shown tremendous potential to combat obesity through different mechanisms. To date, the most active biological constitutes identified in citrus fruits are flavonoids and $p$-synephrine. These exert anti-obesity effects through multiple mechanisms, including regulating energy intake and expenditure, regulating lipid metabolism and regulating adipogenesis. In this mini review, a survey focusing on citrus phytochemicals and their anti-obesity activities is presented, together with an update of findings over the last 10 years, including active components and mechanisms of anti-obesity activities.
\end{abstract}

Keywords: Obesity; Natural Materials; Citrus phytochemicals; Flavonoids; $P$-synephrine; Anti-obesity mechanism.

\section{Introduction}

Citrus plants are a rich source of phytochemicals. The major phytochemicals in citrus include polyphenols and alkaloids. Limonoids have also been reported to benefit human health. To date, several excellent reviews regarding the anti-obesity effects and mechanisms of natural products have been published. In 2010, Yun (2010) reviewed potential anti-obesity of natural therapeutics. Five years later, Lai et al. (2015) reviewed molecular mechanism of functional food bioactives for anti-obesity ). More recently, phytochemicals that prophylactically influence gut microbiota for the treatment of obesity have been reviewed by Carrera-Quintanar et al. (2018). However, no recent reviews have focused specifically on citrus phytochemicals and their anti-obesity effects. Therefore, this mini-review aims to update the literature covering citrus phytochemicals with anti-obesity activity over the past 10 years, including active components and their mechanisms of action (Figure $1)$.

\section{Obesity and anti-obesity drugs}

Obesity is a chronic condition that results from an energy imbalance between calories consumed versus those expended. It can develop from a genetic predisposition, a highly caloric diet, a lack of physical activity and/or an individual's unhealthy lifestyle (Bouchard, 2009). Typically considered as a problem in high-income countries in the past, the occurrence of obesity is now increasing in underdeveloped and developing countries. Globally, the current trend for increased energy-dense food ingestion coupled with decreased physical activity has resulted in over 650 million adults diagnosed as obese and over 380 million children reported overweight or obese in 2016 alone (World Health Organization, WHO). Body mass index (BMI) is a parameter that represents an individual's weight in relationship to height. According to WHO, obesity is defined as a BMI $\geq 30$ (adult), indicating excessive fat accumulation at levels that could harm health. Increased BMI is generally coupled with an increased risk of weight-related illnesses such as 


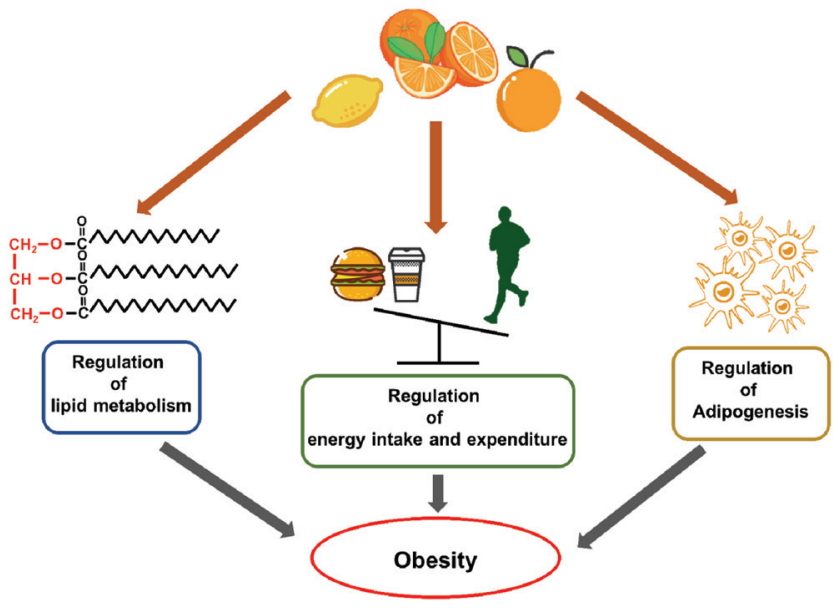

Figure 1. Citrus phytochemicals and their anti-obesity activities.

cardiovascular diseases, diabetes, and some cancers (Heber, 2009). Therefore, obese individuals are more inclined to experience an earlier death.

Early anti-obesity pharmacotherapies included dinitrophenol (Cutting et al., 1933), amphetamines (Heal et al., 2013) and amphetamine derivatives (Araujo and Martel, 2012). Unfortunately, many of these were discontinued or restricted to short-term use due to efficacy and safety concerns such as toxic hyperthermic effects (Colman, 2005; Tainter et al., 1934), addictive properties (Colman, 2005), and potential causes of neuropsychiatric disorders (An et al., 2013). Phentermine, an amphetamine derivative, is still used today, but under strict control, and only as a long-term treatment if combined with other weight-loss therapies (Haslam, 2016). Orlistat was the first non-amphetamine-based anti-obesity drug to be approved in the United States, and is still available today (Rucker et al., 2007). However, resulting gastrointestinal side effects, such as abdominal pain and discomfort, limit its long-term tolerability. Over the past few decades, investigations into the clinical manifestations of obesity have been conducted to improve the understanding behind the pathophysiology of obesity. New information regarding anti-obesity mechanism pathways has revealed new potential targets for drug development in the treatment of obesity. In the past several years, several efficient and safe medications with potential as long-term weight-loss pharmacotherapies have been developed. Current Food and Drug Administration (FDA) approved long-term anti-obesity drugs include Orlistat, Lorcaserin, Phentermine/extended-release topiramate, Naltrexone/bupropion and liraglutide (National Institute of Diabetes and Digestive and Kidney Disease). These medications aim to reduce intestinal fat absorption from food by inhibiting pancreatic lipase, regulating serotonin receptors in the brain to decrease appetite and curb the desire to eat. Although approved for long-term use, current antiobesity therapies result in non-negligible and hazardous side effects including increased blood pressure, rapid pulse, dry mouth, constipation, diarrhea, headache and insomnia, with many still undergoing post-marketing surveillance studies to evaluate longterm safety.

\section{Natural materials for obesity treatment}

Due to the limitation and dissatisfaction with current anti-obesity therapies, alternative therapies such as dietary modifications and acupuncture (Shiraishi et al., 2003) are favored for losing weight in a healthy way. Dietary supplementation available in the market, such as conjugated linoleic acid (CLA) (Gaullier et al., 2004), chitosan (Gades and Stern, 2002) and Garcinia Cambogia (Heymsfield et al., 1998) are also used for weight management. However, information on their efficacy or safety is limited. Meanwhile, exploration into potential anti-obesity effects of natural products has been broadly conducted in recent years. A wide variety of bioactive components from nature (phytochemicals) have demonstrated a reduction in body weight and diet-induced obesity prevention. Phytochemicals are bioactive non-nutrient plant compounds known to reduce the risk of major chronic diseases after ingestion (Liu, 2004). It is recognized that numerous natural materials have different chemical and pharmacological features.

Naturally occurring phytochemicals expressing anti-obesity effects do so by these general mechanisms: 1) decreasing lipid absorption by inhibiting pancreatic lipase activity, 2) suppressing energy intake by controlling appetite, 3) stimulating energy expenditure, 4) inhibiting adipogenesis and 5) regulating lipid metabolism. Many of these display anti-obesity activity based on one or more of the above mechanisms (Yun, 2010). Lipid absorption is decreased by pancreatic lipase, one of the most broadly studied targets based on its ability to facilitate dietary fat absorption in the intestine. Therefore, the efficacy of natural products to inhibit pancreatic lipase has been widely studied. Various types of tea have been thoroughly investigated for pancreatic lipase inhibiting attributes against functional components and different polyphenol types (Lin et al., 2006; Thielecke and Boschmann, 2009). Other natural products, such as Satsuma mandarin (Citrus unshiu) hesperidin, have been illustrated as a porcine pancreas lipase inhibitor (Kawaguchi et al., 1997). In summary, major phytochemicals that possess pancreatic lipase inhibitory effects include saponins, polyphenols, and caffeine (Yun, 2010). Suppressing energy intake is to control appetite and regulate satiety. Natural appetite suppressants, such as tea (Camellia sinensis) (Moon et al., 2007), Caralluma fimbriata (Kuriyan et al., 2007), sour orange (Citrus aurantium) (Klontz et al., 2006), and pomegranate leaf extract (Lei et al., 2007), have been reported. Important active components in these natural products are identified as saponins and flavonoids. Energy is expended in several manners categorized as: (1) physical activity, (2) obligatory energy expenditure, and (3) adaptive thermogenesis. Green tea and its extract have been largely investigated as energy expenditure promoting due to catechins (Wolfram et al., 2006). Additionally, sour orange compounds are considered thermogenic, weight-reducing agents (Preuss et al., 2002). Other natural products, such as extracts of Pinellia ternate (Kim et al., 2006) and Panax ginseng (berry) (Attele et al., 2002), are also known for enhancing energy expenditure. Adipocytes are responsible for the maintenance of lipid homeostasis and energy balance. According to changes in energy demand, adipocytes store triacylglycerols and release free fatty acids. Adipocyte tissue grows through hyperplasia and hypertrophy, making the processes of adipocyte proliferation and differentiation two major targets in anti-obesity studies. Phytochemicals, such as resveratrol, capsaicin, quercetin, genistein, have been found to inhibit adipocyte differentiation and induce apoptosis (Attele et al., 2002; Hsu and Yen, 2007; Hwang et al., 2005). Extensively researched, tea has also shown regulatory effects on lipid metabolism. Oolong and other tea varieties contain caffeine as one major bioactive component and has demonstrated lipolytic activity (Han et al., 1999). Similarly, consumption of green tea extract has shown an increase in fat oxidation (Westerterp-Plantenga et al., 2006). In addition, lipolytic effects of polyphenolic citrus extract has also been observed (Dallas et al., 2008). In addition to the five basic anti-obesity mechanisms, phytochemi- 
<smiles>CNC[C@@H](O)c1ccc(O)cc1</smiles><smiles>CNC[C@H](O)c1ccc(O)cc1</smiles>

p-synephrine<smiles>CNC[C@@H](O)c1cccc(O)c1</smiles><smiles>CNC[C@@H](O)c1cccc(O)c1</smiles>

m-synephrine<smiles>CN[C@@H](C)[C@H](O)c1ccccc1</smiles><smiles>CN[C@@H](C)[C@H](O)c1ccccc1</smiles>

ephedrine

Figure 2. Chemical structures of $p$-synephrine, $m$-synephrine and ephedrine.

cal influence on gut microbiota for the treatment of obesity has attracted much attention in recent years. The influence of the gut microbiota on human health and disease has become increasingly clearer. It is now known that an imbalance of gut microbiota may be the cause, or at least may lead to obesity progression. Therefore, gut microbiota is a potential target for nutritional interventions designed to combat obesity. For this reason, phytochemicals that influence gut microbiota have been studied as adjuvants for the treatment of obesity. For instance, a variety of polyphenols were investigated in several experimental nutritional interventions, and their modification of gut microbiota exerting effects on obesity has been exhaustively reviewed (Carrera-Quintanar et al., 2018). As discussed above, many bioactive plant components demonstrate anti-obesity activities regarding multiple mechanisms. Therefore, anti-obesity treatments using numerous functional components each with multiple activities might be the most efficient approach in the future. Notably, despite establishing the short-term therapeutic efficacy of many natural products, the long-term safety profile of these natural occurring materials is unclear and requires further investigation.

\section{Citrus phytochemicals and their anti-obesity effects}

\subsection{Citrus aurantium and its effects on anti-obesity}

Citrus aurantium, usually known as sour orange or bitter orange, has been considered to possess the most potential as a natural obesity treatment from the citrus family for (Haaz et al., 2006). Its extract, which is usually derived from the unripe fruit, has already been widely used as a dietary supplement for weight loss. The most abundant active phytochemical of sour orange extract is protoalkaloid $p$-synephrine (Nelson et al., 2007; Roman et al., 2007), a phenylethanolamine derivative with the hydroxyl group in the para-position on the benzene ring of the molecule (Pellati et al., 2005) (Figure 2). p-Synephrine is a sympathomimetic drug (adrenergic amine) that imitates the effects of endogenous agonists of the sympathetic nervous system (Bent et al., 2004), and is involved in the regulation of energy. It works primarily as a $\beta-3$ adrenergic agonist (Stohs et al., 2011). The activation of $\beta-3$ adrenoreceptors appear to be responsible for reducing food intake and weight gain in rats, enhancing lipolysis in adipose tissue, and improving insulin resistance, glycemic control, and lipid profiles (Arch, 2002; Hamilton and Doods, 2008; Oana et al., 2005). Therefore, when $p$-synephrine activates $\beta-3$ adrenoreceptors, an increase in thermogenesis and lipolysis is expected. Indeed, several animal studies have shown the intake of p-synephrine or sour orange extract leads to weight loss or decreased weight gain (Arbo et al., 2009; Titta et al., 2010). Some limited human studies have implied that consumption of sour orange extract reduced body weight, which is likely to be associated with enhanced metabolism, suppressed appetite via reducing gut motility, and promoted lipolysis in adipocytes (Haaz et al., 2006; Hess and Sullivan, 2005). Other citrus species, such as sweet orange, mandarin and grapefruits also contain $p$-synephrine (Dragull et al., 2008; Sander et al., 2008; Uckoo et al., 2011). It has been documented that a Satsuma mandarin segment wall extract rich in p-synephrine induced lipolysis in rat adipose cells (Tsujita and Takaku, 2007).

Sour orange extract has been popular and marketed as a safe weight-loss product since beginning of the 21 st century. The biggest dispute regarding the wide use of sour orange extract $/ p$-synephrine is that research indicates an association of consumption with various cardiovascular hazards. From 2004 to 2009, the FDA received multiple reports of adverse effects regarding products containing sour orange extract, which were supported by several clinical studies. However, these conclusions indicating sour orange extract and $p$-synephrine are responsible for adverse effects was later shown to be unjustified in an review article (Stohs, 2010). The concern regarding sour orange extract $/ p$-synephrine is mainly due to $p$-synephrine's structural similarities with ephedrine, as well as the misconception between $p$-synephrine and its isomer, m-synephrine. Ephedrine was commonly used as a dietary supplement for weight loss and weight management, before being banned by the FDA due to health concerns in 2004. It is structurally related to $p$-synephrine (Figure 2). $m$-Synephrine (Figure 2), also known as phenylephrine, has a hydroxyl group in the meta-position on the benzene ring. Both ephedrine and $m$-synephrine have been associated with cardiovascular risks in various studies. In fact, ephedrine and $\mathrm{m}$-synephrine are not detected in sour orange (Pellati and Benvenuti, 2007), and the structural differences between $p$-synephrine with ephedrine and $m$-synephrine lead to different receptor binding characteristics and pharmacokinetic properties. The binding of ephedrine and $m$-synephrine to $\alpha$-adrenoreceptors as well as $\beta-1$ and $\beta-2$ adrenoreceptors produce vasoconstriction, cardiovascular contractility, increased heart rate and bronchodilation (Inchiosa, 2010), whereas $p$-synephrine shows little binding affinity for $\alpha$ - as well as $\beta-1$ and $\beta-2$ adrenoreceptors, even though they possess similar chemical structures (Bent et al., 2004; Coates et al., 2004; Fugh-Berman and Meyers, 2004; Penzak et al., 2001). Therefore, compared to ephedrine and $m$-synephrine, $p$-synephrine shows little, if any, CNS and cardiovascular stimulation. Despite being considered safe thus far, there are very limited studies involving the administration of $p$-synephrine alone regarding weight loss. Consequently, in the last 10 years, investigations on the antiobesity effects of sour orange have been continually conducted. In 2008, the concentration of $p$-synephrine in unripe fruits and leaves from sour orange was determined and the acute toxicity of sour orange extract and $p$-synephrine was also evaluated (Arbo et 
al., 2008). These results indicated that sour orange fruit contained about 0.04 to $0.05 \%$ of $p$-synephrine, whereas the leaves contained around $0.006 \%$ of $p$-synephrine. Acute oral administration of sour orange extracts $(2.5 \%$-synephrine, $300-5,000 \mathrm{mg} / \mathrm{kg})$ in mice resulted in a reduction of locomotor activity, whereas $p$-synephrine $(150-2,000 \mathrm{mg} / \mathrm{kg})$ caused piloerection, gasping, salivation, exophtalmia and reduction in locomotor activity. One year later, sour orange extract and $p$-synephrine's subchronic toxicity in mice and its actions in oxidative stress biomarkers was studied. A commercial sour orange dried extract (containing $7.5 \%$ p-synephrine) 400 , 2,000 or $4,000 \mathrm{mg} / \mathrm{kg}$ and $p$-synephrine 30 or $300 \mathrm{mg} / \mathrm{kg}$ was given to mice for 28 consecutive days using oral gavage. An increase in reduced glutathione concentration in mice treated with sour orange extract 4,000 mg/kg and $p$-synephrine 30 and $300 \mathrm{mg} / \mathrm{kg}$ was observed. For glutathione peroxidase, sour orange 400 and 2,000 $\mathrm{mg} / \mathrm{kg}$ and $p$-synephrine 30 and $300 \mathrm{mg} / \mathrm{kg}$ treated mice showed inhibition of the activity. Therefore, a low subchronic toxicity of the tested sour orange extract and p-synephrine in mice resulted in a possible alteration of oxidative metabolism. Interestingly, effects of sour orange extracts and $p$-synephrine on metabolic fluxes in the rat liver were also evaluated (Peixoto et al., 2012). Increased glycogenolysis, glycolysis, oxygen uptake and perfusion pressure were observed with sour orange extracts and $p$-synephrine treatments. Since many increased actions are generally catabolic in nature, the author concluded that those actions were compatible with the weight-loss effects due to sour orange ingestion. In addition to the animal study, sour orange extract/p-synephrine was also investigated as a single ingredient product in human studies. In a study regarding effects of $p$-synephrine on resting metabolism, blood pressure, heart rate and self-reported mood changes, the subject group treated with $p$-synephrine $(50 \mathrm{mg})$ exhibited no changes in heart rate or blood pressure compared with the control group, and there was no change in self-reported ratings of 10 symptoms between the $p$-synephrine group and the control group (Stohs et al., 2011). A double-blind, placebo-controlled safety study involving sour orange extract indicated that sour orange extract and psynephrine appeared to be without adverse effects at a dose of up to $98 \mathrm{mg}$ per day for 60 days (Kaats et al., 2013). In a most recent investigation, cardiovascular effects of bitter orange extract (49 mg p-synephrine) on healthy subjects in a double blind, placebocontrolled, crossover study was assessed. No significant changes were observed in electrocardiograms, heart rates, systolic blood pressure, blood chemistries, or blood cell counts in $p$-synephrine treated group (Shara et al., 2016).

Based on the discussion above, there is not enough evidence connecting sour orange extract $/ p$-synephrine with significant adverse events. Nevertheless, further longer-term human studies are necessary to better elucidate the effects of $p$-synephrine on weight management and verify the safety data. Moreover, additional studies regarding $p$-synephrine adrenoreceptor binding are necessary to better understand how to achieve safety and efficacy of sour orange extract $/ p$-synephrine.

\subsection{Other citrus fruits and their effects on anti-obesity}

As reviewed in section 3, polyphenols, the secondary metabolites of plants, represent the largest category of phytochemicals to combat obesity. They include a large group of compounds with complex chemical structures, that are divided into four main groups, i.e. flavonoids, phenolic acids, stilbenoids and lignans. In the plant kingdom, more than 8,000 polyphenols have been identified (Pandey and Rizvi, 2009). Among all the naturally occurring products, citrus fruit is one of the most abundant source of flavonoids, es- pecially in the citrus peel. This explains the intensity of investigations into citrus peel extract and its anti-obesity effects (Ezekwesili-Ofili and Gwacham, 2015; Huang et al., 2009). Flavonoids are further classified into seven subgroups, including flavones, flavonols, flavanones, flavanonols, flavanols, anthocyanins and isoflavones. Among them, flavanones, flavones and flavanonols are mainly found in citrus fruits. According to numerous epidemic studies over recent decades, possible mechanisms of anti-obesity activity attributed to citrus flavonoids can be summarized by the following regulations: regulation of energy intake and expenditure, regulation of lipid metabolism and regulation of adipogenesis (Feng et al., 2017). In addition to polyphenols, oxygenated triterpenoids called limonoids also possess strong potential as a class of compounds with pharmacological activities. Two major limonoids, limonin and nomilin are also abundant in citrus fruits. In this section, citrus research focuses on anti-obesity effects attributed to flavonoids and limonoinds over the past 10 years are reviewed and discussed according to their possible mechanisms (Table 1).

\subsubsection{Regulation of lipid metabolism}

Obesity is characterized by lipid metabolism disorder. In general, reducing lipogenesis and promoting lipolysis are two key approaches to treat or reverse obesity, making them two selective targets of citrus phytochemicals. Lipogenesis is the process where free fatty acids are stored within lipid droplets as triglycerides. In an animal study, Citrus depressa Hayata (shiikuwasa) peel extract was shown to significantly decrease body weight gain, as well as white adipose tissue weight in obese mice (Lee et al., 2011). Meanwhile, decreased plasma triglyceride and leptin levels and smaller sized adipocytes were also reported for the peel extract treated group. Significantly lower mRNA levels of lipogenesis-related genes, such as activating protein 2, stearoyl-CoA desaturase 1 (SCD1), acetyl-CoA-carboxylase 1 (ACC1), fatty acid transport protein and diacylglycerol acyltransferase 1 in the peel extract treated group indicated the activities of citrus peel extract on the regulation of lipogenesis. Lipolysis is the process where triacylglycerols stored in adipocytes are metabolized to free fatty acids and glycerol. In the adipocytes, the initiation of lipolysis is regulated by a variety of hormones including epinephrine and adrenocorticotropic hormone, which are regulated by cAMP cascade. Lipolytic hormones enhance the synthesis of cAMP, resulting in activation of cAMPdependant protein kinase and activation of hormone-sensitive lipase (HSL). Activation of HSL leads to the hydrolysis of stored triglycerides into free fatty acids and glycerol. The inhibition of cAMP-dependent phosphodiesterase (PDE) increases cyclic cAMP and consequently activates HSL. In a human clinical study, SINETROL, a citrus-based polyphenolic dietary supplement, decreased the body fat of overweight volunteers, which was attributed to its inhibitory effect on cAMP-phosphodiesterase (PDE). Similarly, immature Citrus sunki peel extract (CSE) reportedly enhanced lipolysis through phosphorylation of cAMP-dependent protein kinase and HSL in mature 3T3-L1 adipocytes (Kang et al., 2012). In the same paper, CSE also demonstrated the ability to increase phosphorylation levels of AMP-activated protein kinase (AMPK) and acetyl-CoA carboxylase (ACC) in epididymal adipose tissue, as well as mature 3T3-L1 adipocytes that eventually led to increased $\beta$-oxidation. Moreover, extract of Chenpi (the dry peel of the plant Citrus reticulata after an aging process), rich in 5-demethylated polymethoxyflavones has been reported to activate the AMPK signaling pathway (Guo et al., 2016).

Peroxisome proliferator-activated receptor (PPAR)- $\alpha$ is a ligand-activated transcription factor that plays a crucial role in lipid 
Table 1. Citrus phytochemical studies on anti-obesity effects

\begin{tabular}{|c|c|c|c|}
\hline Source & Mechanism & Experimental model & Reference \\
\hline $\begin{array}{l}\text { SINETROL (citrus-based } \\
\text { polyphenolic dietary supplement) }\end{array}$ & Inhibition of cAMP-phosphodiesterase (PDE) & $\begin{array}{l}\text { Cell model and } \\
\text { human clinical study }\end{array}$ & Dallas et al. (2008) \\
\hline Blood orange juice & Not clear & Mouse model & Titta et al. (2010) \\
\hline Orange peel extract & Suppressing adipose tissue formation & Mouse model & Huang et al. (2009) \\
\hline $\begin{array}{l}\text { Citrus (orange, lemon, } \\
\text { lime, tangerine and } \\
\text { grapefruit) peels extract }\end{array}$ & Not clear & Rat model & $\begin{array}{l}\text { Ezekwesili-Ofili and } \\
\text { Gwacham (2015) }\end{array}$ \\
\hline $\begin{array}{l}\text { Citrus depressa hayata } \\
\text { (shiikuwasa) peel extract }\end{array}$ & $\begin{array}{l}\text { Regulating the expressions of lipogenesis- } \\
\text { related genes in white adipose tissue }\end{array}$ & Mouse model & Lee et al. (2011) \\
\hline Immature Citrus sunki peel extract & $\begin{array}{l}\text { Promoting } \beta \text {-oxidation and } \\
\text { lipolysis in adipose tissue }\end{array}$ & $\begin{array}{l}\text { Mouse model and } \\
\text { 3T3-L1 cell model }\end{array}$ & Kang et al. (2012) \\
\hline Aged citrus (Chenpi) peel extract & $\begin{array}{l}\text { Improvement in lipid metabolism associated } \\
\text { with activation of the AMPK pathway }\end{array}$ & Mouse model & Guo et al. (2016) \\
\hline Grapefruit naringenin & $\begin{array}{l}\text { Regulating the activity of nuclear } \\
\text { receptors PPAR } \alpha \text {, PPAR } \gamma \text {, and LXR } \alpha \text { s }\end{array}$ & Cell model & $\begin{array}{l}\text { Goldwasser et } \\
\text { al. (2010) }\end{array}$ \\
\hline Pomelo peel extracts & Activate PPAR $\alpha$ and GLUT4 pathway & Mouse model & Ding et al. (2013) \\
\hline $\begin{array}{l}\text { Yuzu (Citrus juno) peel } \\
\text { and pomace extracts }\end{array}$ & Activate hepatic PPAR $\alpha$ and adipocyte PPAR $\gamma$ & Zebrafish model & Zang et al. (2014) \\
\hline Lemon peel polyphenols & $\begin{array}{l}\text { Increasing peroxisomal } \beta \text {-oxidation } \\
\text { through Up-regulation of mRNA levels of } \\
\text { PPAR } \alpha \text { and acyl-CoA oxidase (ACO) }\end{array}$ & Mouse model & Fukuchi et al. (2008) \\
\hline Citrus peel extract & $\begin{array}{l}\text { Regulating the LD perilipin } 1 \text { protein and } \\
\text { transcriptional factor SREBP-1 protein } \\
\text { expression and altering gut microbiota }\end{array}$ & $\begin{array}{l}\text { Mouse model and } \\
\text { 3T3-L1 cell model }\end{array}$ & Tung et al. (2018) \\
\hline $\begin{array}{l}\text { Sour orange (Citrus } \\
\text { aurantium) flavonoids }\end{array}$ & $\begin{array}{l}\text { Inhibit adipogenesis through } \\
\text { the Akt signaling pathway }\end{array}$ & 3T3-L1 cell model & Kim et al. (2012) \\
\hline $\begin{array}{l}\text { Citrus ichangensis } \\
\text { peel extract }\end{array}$ & Inhibition of PPAR $y$ and LXR signaling & Mouse model & Ding et al. (2012) \\
\hline $\begin{array}{l}\text { Dried Satsuma mandarin } \\
\text { (C. unshiu) peel extract }\end{array}$ & $\begin{array}{l}\text { Indirectly stimulate lipolysis by inhibiting } \\
\text { protection of physical barrier on lipid droplet to } \\
\text { hinder lipid accumulation in 3T3-L1 adipocytes }\end{array}$ & 3T3-L1 cell model & Jung et al. (2011) \\
\hline $\begin{array}{l}\text { Morosil (Blood orange } \\
\text { juice extract) }\end{array}$ & Not clear & Human clinical study & Cardile et al. (2015) \\
\hline $\begin{array}{l}\text { Citrus aurantifolia (key } \\
\text { lime) essential oil }\end{array}$ & Suppressing appetite & Mouse model & $\begin{array}{l}\text { Asnaashari et } \\
\text { al. (2010) }\end{array}$ \\
\hline Nomilin standard & Activation of TGR5 receptor & Mouse model & Ono et al. (2011) \\
\hline
\end{tabular}

metabolism. Goldwasser et al. reported that the grapefruit flavonoid naringenin is capable of inducing PPAR-regulated fatty acid oxidation genes such as CYP4A11, UCP1 and ApoAI, and inhibiting LXR $\alpha$-regulated lipogenesis genes, such as FAS, ABCG1, and HMGR in hepatocytes (Goldwasser et al., 2010). Similarly, Ding et al. reported pomelo peel extract increased the mRNA expression of PPAR $\alpha$ and its target genes, such as FAS, PGC- $1 \alpha$ and PGC-1 $\beta$ in the liver and white adipocyte tissue (WAT), which consequently elevated $\beta$-oxidation (Ding et al., 2013). Interestingly, Zang et al. evaluated the effects of yuzu peel and yuzu pomace extracts on metabolic disorders in zebrafish (Zang et al., 2014). Both yuzu peel and pomace exhibited anti-obesity effects, specifically, yuzu peel significantly up-regulated the hepatic mRNA expression of PPAR $\alpha$ and its target genes, implying enhanced fatty acid $\beta$-oxidation in the liver. Finally, lemon polyphenols administration was demonstrated with increased peroxisomal $\beta$-oxidation through up-regulation of the mRNA level of acyl-CoA oxidase (ACO) and PPAR $\alpha$, which suppressed body weight gain and body fat accumulation in mice (Fukuchi et al., 2008).

In addition, Tung et al. (2018) reported that citrus peel extracts reduced adipocyte size in the perigonadal fat by decreasing levels of perilipin 1 protein, as well as sterol regulatory element binding protein 1 (SREBP-1) expression..Perilipin 1 is involved in the formation of lipid droplets in WAT, whereas SREBP-1 is a lipogenesis-related gene. More interestingly, in the same study, altered gut microbiota composition attributed to peel extract was observed by increasing Prevotella and decreasing rc4-4 bacteria. Since the change in the composition of gut microbiota may determine metabolic health, the result proposed modification of gut microbiota as a potential mechanism for fighting obesity. 


\subsubsection{Regulation of adipogenesis}

Adipose tissue plays a crucial role in lipid homeostasis in the human body. As caloric intake increases, adipose tissue grows via adipogenesis. Adipogenesis is a process during which preadipocytes and fibroblast-like preadipocytes develop into mature adipocytes (Ali et al., 2013). This generation of new adipocytes is controlled by several transcription factors regulating preadipocyte proliferation and adipogenesis, such as the CCAAT-enhancer-binding proteins (C/EBPs) family, peroxisome proliferator-activator receptor $\gamma(\mathrm{PPAR} \gamma)$ and cyclic AMP responsive element binding protein (CREB). All of these are responsible for the transactivation of adipocyte genes involved in morphological changes of the cell, lipid metabolism, and synthesis of adipocyte-specific peptides and cytokines during terminal differentiation ( Kim and Park, 2011). Although well known for containing anti-obesity phytochemical p-synephrine, sour orange is also a good resource of flavonoids. In a cell study, sour orange flavonoids (CAF) were shown to suppress adipogenesis in 3T3-L1 adipocytes (Kim et al., 2012). Their results indicated that $\mathrm{CAF}$ down-regulates the expression of $\mathrm{C} / \mathrm{EBP} \beta$ and subsequently inhibits the activation of PPAR $\gamma$ and C/EBP $\alpha$. Similarly, inhibition of PPAR $\gamma$ was also demonstrated in the investigation of Citrus ichangensis peel extract using high-fat (HF) dietinduced obesity mice (Ding et al., 2012). In another study, citrus peel extract slightly inhibited the expression of adipogenesis-related transcription factors such as $\mathrm{C} / \mathrm{EBP} \alpha, \operatorname{PPAR} \gamma$, and sterolregulatory element binding protein 1 (SREBP1) in 3T3-L1 adipocytes (Jung et al., 2011). Meanwhile, in the same study, peel extract was found to indirectly promote lipolysis by down-regulating gene expression of perilipin, which binds and stabilizes lipid droplets and controls fatty acid release. The decrease of perilipin production weakened the physical barrier impeding the action of lipase on lipid droplets, and consequently facilitated lipolysis.

\subsubsection{Other mechanisms}

In the last decade, several studies have assessed the anti-obesity beneficial effects of blood orange juice. Moro orange, a cultivar of blood orange, is particularly rich in active components such as anthocyanins, hydroxycinnamic acids, flavone glycosides and ascorbic acid. The anti-obesity effects of Moro juice have been reported by both Cardile et al. (2015) and Titta et al. (2010). In addition to blood orange, Asnaashari et al. reported that lime (Citrus aurantifolia) essential oils could reduce body weight and food consumption in mice, possibly through promoting anorexia (Asnaashari et al., 2010). Ono et al. observed citrus nomilin attenuated diet-induced obesity in mice by acting as an activator of TGR5 (Ono et al., 2011), a member of the G protein-coupled receptor family that has recently become a popular therapeutic target for the treatment of obesity (Zhong, 2010).

\section{Conclusions}

Obesity is a chronic inflammatory disease that has spread globally. The use of current anti-obesity drugs is related to multiple, adverse side effects and uncertain long-term risks. Therefore, natural alternatives with active phytochemicals, such as citrus fruits, are a popular target in the search for safe anti-obesity therapies. Current knowledge indicates major phytochemicals from citrus fruits that exert anti-obesity effects are flavonoids and $p$-synephrine. Meanwhile, an increasing understanding of the possible anti-obesity mechanisms, including regulation of lipid metabolism, regulation of energy intake and expenditure and regulation of adipogenesis, have been facilitated with intense investigations into different citrus fruits and different segments of the fruits. Numerous in vitro and in vivo studies have shown that citrus fruits are considered a strong potential source for developing novel anti-obesity therapies. Nevertheless, it is necessary to further assess the pharmacological effects and safety of citrus phytochemicals through sufficient appropriately designed and conducted trials, and eventually, clinical human studies. In addition, since many citrus studies have looked at crude extracts of citrus fruit (e.g. citrus peel extract), more efforts should focus on exploring and clarifying the specific functional components in citrus fruit. Finally, the investigation of unknown mechanism-related issues within the reported studies and beyond should be continued. Currently, citrus crops are mainly consumed as fresh fruit or juice beverages, and analysis results applied to the flavor, nutraceutical and perfumery industries. Therefore, utilization of citrus fruits for developing dietary supplements and functional foods may help to provide safer options for obese or pre-obese individuals to prevent and fight this disease.

\section{Acknowledgments}

The authors are thankful to Laura Reuss for editing the manuscript.

\section{Conflict of interest}

There are no conflicts of interest to declare.

\section{References}

Ali, A.T., Hochfeld, W.E., Myburgh, R., and Pepper, M.S. (2013). Adipocyte and adipogenesis. Eur. J. Cell Biol. 92(6): 229-236.

An, H., Sohn, H., and Chung, S. (2013). Phentermine, sibutramine and affective disorders. Clin. Psychopharmacol. Neurosci. 11(1): 7.

Araujo, J.R., and Martel, F. (2012). Sibutramine effects on central mechanisms regulating energy homeostasis. Curr. Neuropharmacol. 10(1): 49-52.

Arbo, M.D., Larentis, E.R., Linck, V.M., Aboy, A.L., Pimentel, A.L., Henriques, A.T., Dallegrave, E., Garcia, S.C., and Limberger, R.P. (2008). Concentrations of $p$-synephrine in fruits and leaves of Citrus species (Rutaceae) and the acute toxicity testing of Citrus aurantium extract and $p$-synephrine. Food Chem. Toxicol. 46(8): 2770-2775.

Arbo, M.D., Schmitt, G.C., Limberger, M.F., Charão, M.F., Moro, A.M., Ribeiro, G.L., Dallegrave, E., Garcia, S.C., and Limberger, R.P. (2009). Subchronic toxicity of Citrus aurantium L.(Rutaceae) extract and $p$ synephrine in mice. Regul. Toxicol. Pharmacol. 54(2): 114-117.

Arch, J.R. (2002). $\beta 3$-Adrenoceptor agonists: potential, pitfalls and progress. Eur. J. Cell Biol. 440(2-3): 99-107.

Asnaashari, S., Delazar, A., Habibi, B., Vasfi, R., Nahar, L., Hamedeyazdan, S., and Sarker, S.D. (2010). Essential oil from Citrus aurantifolia prevents ketotifen-induced weight-gain in mice. Phytother. Res. 24(12): 1893-1897.

Attele, A.S., Zhou, Y.-P., Xie, J.T., Wu, J.A., Zhang, L., Dey, L., Pugh, W., Rue, P.A., Polonsky, K.S., and Yuan, C.S. (2002). Antidiabetic effects of Panax ginseng berry extract and the identification of an effective component. Diabetes. 51(6): 1851-1858.

Bent, S., Padula, A., and Neuhaus, J. (2004). Safety and efficacy of Citrus aurantium for weight loss. Am. J. Cardiol. 94(10): 1359-1361.

Bouchard, C. (2009). Defining the genetic architecture of the predisposition to obesity: a challenging but not insurmountable task. Am. J. Clin. Nutr. 91(1): 5-6.

Cardile, V., Graziano, A.C.E., and Venditti, A. (2015). Clinical evaluation of 
Moro (Citrus sinensis (L.) Osbeck) orange juice supplementation for the weight management. Nat. Prod. Res. 29(23): 2256-2260.

Carrera-Quintanar, L., López Roa, R.I., Quintero-Fabián, S., SánchezSánchez, M.A., Vizmanos, B., and Ortuño-Sahagún, D. (2018). Phytochemicals that influence gut microbiota as prophylactics and for the treatment ofobesity and inflammatory diseases. Mediators Inflamm. 2018: 1-18.

Coates, P.M., Blackman, M.R., Cragg, G.M., Levine, M., Moss, J., and White, J.D. (2004). Encyclopedia of Dietary Supplements CRC Press, Boca Raton, FL.

Colman, E. (2005). Anorectics on trial: a half century of federal regulation of prescription appetite suppressants. Ann Intern Med. 143(5): 380-385.

Cutting, W., Mehrtens, H., and Tainter, M. (1933). Actions and uses of dinitrophenol: promising metabolic applications. JAMA 101(3): 193-195.

Dallas, C., Gerbi, A., Tenca, G., Juchaux, F., and Bernard, F.X. (2008). Lipolytic effect of a polyphenolic citrus dry extract of red orange, grapefruit, orange (SINETROL) in human body fat adipocytes. Mechanism of action by inhibition of cAMP-phosphodiesterase (PDE). Phytomedicine. 15(10): 783-792.

Ding, X., Fan, S., Lu, Y., Zhang, Y., Gu, M., Zhang, L., Liu, G., Jiang, D., Lu, X., $\mathrm{Li}, \mathrm{Y}$., Zhou, Z., and Huang, C. (2012). Citrus ichangensis peel extract exhibits anti-metabolic disorder effects by the inhibition of PPAR and LXR signaling in high-fat diet-induced C57BL/6 mouse. Evid. Based Complement. and Alternat. Med. 2012: 678592.

Ding, X., Guo, L., Zhang, Y., Fan, S., Gu, M., Lu, Y., Jiang, D., Li, Y., Huang, C., and Zhou, Z. (2013). Extracts of pomelo peels prevent high-fat dietinduced metabolic disorders in $\mathrm{c57bl} / 6$ mice through activating the PPAR $\alpha$ and GLUT4 pathway. Plos one 8(10): e77915.

Dragull, K., Breksa III, A.P., and Cain, B. (2008). Synephrine content of juice from Satsuma mandarins (Citrus unshiu Marcovitch). J. Agric. Food Chem. 56(19): 8874-8878.

Ezekwesili-Ofili, J.O., and Gwacham, N.C. (2015). Comparative effects of peel extract from Nigerian grown Citrus on body weight, liver weight and serum lipids in rats fed a high-fat diet. Afr. J. Biochem. Res. 9(9): 110-116.

Feng, S., Reuss, L., Suh, J.H., and Wang, Y. (2017). Citrus flavonoids and their effects on obesity. Phytochemicals in citrus: applications in functional foods In: Ye, X. (Ed.). CRC Press, Taylor \& Francis Group, Boca Raton, FL, pp. 325-346.

Fugh-Berman, A., and Myers, A. (2004). Citrus aurantium, an ingredient of dietary supplements marketed for weight loss: current status of clinical and basic research. Exp. Biol. Med. 229(8): 698-704.

Fukuchi, Y., Hiramitsu, M., Okada, M., Hayashi, S., Nabeno, Y., Osawa, T., and Naito, M. (2008). Lemon polyphenols suppress diet-induced obesity by up-regulation of mRNA levels of the enzymes involved in $\beta$-oxidation in mouse white adipose tissue. J. Clin. Biochem. Nutr. 43(3): 201-209.

Gades, M., and Stern, J. (2002). Chitosan supplementation does not affect fat absorption in healthy males fed a high-fat diet, a pilot study. Int. J. Obesity. 26(1): 119

Gaullier, J.-M., Halse, J., Høye, K., Kristiansen, K., Fagertun, H., Vik, H., and Gudmundsen, O. (2004). Conjugated linoleic acid supplementation for 1 y reduces body fat mass in healthy overweight humans. Am. J. Clin. Nutr. 79(6): 1118-1125.

Goldwasser, J., Cohen, P.Y., Yang, E., Balaguer, P., Yarmush, M.L., and Nahmias, Y. (2010). Transcriptional regulation of human and rat hepatic lipid metabolism by the grapefruit flavonoid naringenin: role of PPAR $\alpha$, PPARY and LXR $\alpha$. Plos One 5(8): e12399.

Guo, J., Tao, H., Cao, Y., Ho, C.T., Jin, S., and Huang, Q. (2016). Prevention of obesity and type 2 diabetes with aged citrus peel (Chenpi) extract. J. Agric. Food Chem. 64(10): 2053-2061.

Haaz, S., Fontaine, K., Cutter, G., Limdi, N., Perumean-Chaney, S., and Allison, D. (2006). Citrus aurantium and synephrine alkaloids in the treatment of overweight and obesity: an update. Obes. Rev. 7(1): 79-88.

Hamilton, B.S., and Doods, H.N. (2008). Identification of potent agonists acting at an endogenous atypical $\beta 3$-adrenoceptor state that modulate lipolysis in rodent fat cells. Eur. J. Pharmacol. 580(1-2): 55-62.

Han, L., Takaku, T., Li, J., Kimura, Y., and Okuda, H. (1999). Anti-obesity action of oolong tea. Int. J. Obesity. 23(1): 98.
Haslam, D. (2016). Weight management in obesity-past and present. Int. J. Clin. Pract. 70(3): 206-217.

Heal, D.J., Smith, S.L., Gosden, J., and Nutt, D.J. (2013). Amphetamine, past and present-a pharmacological and clinical perspective. J. Psychopharmacol. 27(6): 479-496.

Heber, D. (2009). An integrative view of obesity. Am. J. Clin. Nutr. 91(1): 280S-283S

Hess, A.M., and Sullivan, D.L. (2005). Potential for toxicity with use of bitter orange extract and guarana for weight loss. Ann Pharmacother 39(3): 574.

Heymsfield, S.B., Allison, D.B., Vasselli, J.R., Pietrobelli, A., Greenfield, D., and Nunez, C. (1998). Garcinia cambogia (hydroxycitric acid) as a potential antiobesity agent: a randomized controlled trial. JAMA 280(18): 1596-1600.

Hsu, C.L., and Yen, G.C. (2007). Effects of capsaicin on induction of apoptosis and inhibition of adipogenesis in 3T3-L1 cells. J. Agric. Food Chem. 55(5): 1730-1736.

Huang, Y.W., Liu, Y., Dushenkov, S., Ho, C.T., and Huang, M.T. (2009). Antiobesity effects of epigallocatechin-3-gallate, orange peel extract, black tea extract, caffeine and their combinations in a mouse model. J. Funct. Foods. 1(3): 304-310.

Hwang, J.T., Park, I.J., Shin, J.I., Lee, Y.K., Lee, S.K., Baik, H.W., Ha, J., and Park, O.J. (2005). Genistein, EGCG, and capsaicin inhibit adipocyte differentiation process via activating AMP-activated protein kinase. Biochem. Biophys. Res. Commun. 338(2): 694-699.

Inchiosa, M.A. (2010). Experience (mostly negative) with the use of sympathomimetic agents for weight loss. J. Obes. 2011: 1-4.

Jung, H.K., Jeong, Y.S., Park, C.D., Park, C.H., and Hong, J.H. (2011). Inhibitory effect of citrus peel extract on lipid accumulation of 3T3-L1 adipocytes. J. Korean Soc. Appl. Bi. Chem. 54(2): 169-176.

Kaats, G.R., Miller, H., Preuss, H.G., and Stohs, S.J. (2013). A 60 day double-blind, placebo-controlled safety study involving Citrus aurantium (bitter orange) extract. Food Chem. Toxicol. 55: 358-362.

Kang, S.I., Shin, H.S., Kim, H.M., Hong, Y.S., Yoon, S.A., Kang, S.W., Kim, M.H., Ko, H.C., and Kim, S.J. (2012). Immature Citrus sunki peel extract exhibits antiobesity effects by $\beta$-oxidation and lipolysis in highfat diet-induced obese mice. Biol. Pharm. Bull. 35(2): 223-230.

Kawaguchi, K., Mizuno, T., Aida, K., and Uchino, K. (1997). Hesperidin as an inhibitor of lipases from porcine pancreas and Pseudomonas. Biosci. Biotechnol. Biochem. 61(1): 102-104.

Kim, G.S., Park, H.J., Woo, J.H., Kim, M.K., Koh, P.O., Min, W., Ko, Y.G., Kim C.H., Won, C.K., and Cho, J.H. (2012). Citrus aurantium flavonoids inhibit adipogenesis through the Akt signaling pathway in 3T3-L1 cells. BMC Complement. Altern. Med. 12(1): 31.

Kim, K.H., and Park, Y. (2011). Food components with anti-obesity effect. Annu. Rev. Food Sci. Technol. 2: 237-257.

Kim, Y.J., Shin, Y.O., Ha, Y.W., Lee, S., Oh, J.K., and Kim, Y.S. (2006). Antiobesity effect of Pinellia ternata extract in Zucker rats. Biol. Pharm. Bull. 29(6): 1278-1281.

Klontz, K.C., Timbo, B.B., and Street, D. (2006). Consumption of dietary supplements containing Citrus aurantium (bitter orange)-2004 California behavioral risk factor surveillance survey (BRFSS). Ann. PharmacotheR. 40(10): 1747-1751.

Kuriyan, R., Raj, T., Srinivas, S., Vaz, M., Rajendran, R., and Kurpad, A.V. (2007). Effect of Caralluma fimbriata extract on appetite, food intake and anthropometry in adult Indian men and women. Appetite. 48(3): 338-344.

Lai, C.S., Wu, J.C., and Pan, M.H. (2015). Molecular mechanism on functional food bioactives for anti-obesity. Curr. Opin. Food Sci. 2: 9-13.

Lee, Y.S., Cha, B.Y., Saito, K., Choi, S.S., Wang, X.X., Choi, B.K., Yonezawa, T., Teruya, T., Nagai, K., and Woo, J.T. (2011). Effects of a Citrus depressa Hayata (shiikuwasa) extract on obesity in high-fat diet-induced obese mice. Phytomedicine. 18(8-9): 648-654.

Lei, F., Zhang, X., Wang, W., Xing, D., Xie, W., Su, H., and Du, L. (2007) Evidence of anti-obesity effects of the pomegranate leaf extract in high-fat diet induced obese mice. Int. J. Obesity. 31(6): 1023.

Lin, J.K., and Lin-Shiau, S.Y. (2006). Mechanisms of hypolipidemic and anti-obesity effects of tea and tea polyphenols. Mol. Nutr. Food Res. 50(2): 211-217.

Liu, R.H. (2004). Potential synergy of phytochemicals in cancer prevention: mechanism of action. J. Nutr. 134(12): 3479S-3485S 
Moon, H.S., Lee, H.G., Choi, Y.J., Kim, T.G., and Cho, C.S. (2007). Proposed mechanisms of (-)-epigallocatechin-3-gallate for anti-obesity. Chem. Biol. Interact. 167(2): 85-98.

National Institute of Diabetes and Digestive and Kidney Diseases. (2018). Prescription medication to treat overweight and obesity. https://www. niddk.nih.gov/health-information/weight-management/prescriptionmedications-treat-overweight-obesity. Accessed 15 Nov. 2018.

Nelson, B.C., Putzbach, K., Sharpless, K.E., and Sander, L.C. (2007). Mass spectrometric determination of the predominant adrenergic protoalkaloids in bitter orange (Citrus aurantium). J. Agric. Food Chem. 55(24): 9769-9775.

Oana, F., Homma, T., Takeda, H., Matsuzawa, A., Akahane, S., Isaji, M., and Akahane, M. (2005). DNA microarray analysis of white adipose tissue from obese $(\mathrm{fa} / \mathrm{fa})$ Zucker rats treated with a $\beta 3$-adrenoceptor agonist, KTO-7924. Pharmacol. Res. 52(5): 395-400.

Ono, E., Inoue, J., Hashidume, T., Shimizu, M., and Sato, R. (2011). Antiobesity and anti-hyperglycemic effects of the dietary citrus limonoid nomilin in mice fed a high-fat diet. Biochem. Biophys. Res. Commun. 410(3): 677-681.

Pandey, K.B., and Rizvi, S.I. (2009). Plant polyphenols as dietary antioxidants in human health and disease. Oxid. Med. Cell. Longev. 2(5): 270-278.

Peixoto, J.S., Comar, J.F., Moreira, C.T., Soares, A.A., de Oliveira, A.L., Bracht, A., and Peralta, R.M. (2012). Effects of Citrus aurantium (bitter orange) fruit extracts and $p$-synephrine on metabolic fluxes in the rat liver. Molecules. 17(5): 5854-5869.

Pellati, F., and Benvenuti, S. (2007). Chromatographic and electrophoretic methods for the analysis of phenetylamine alkaloids in Citrus aurantium. J. Chromatogr. A. 1161(1-2): 71-88.

Pellati, F., Benvenuti, S., and Melegari, M. (2005). Enantioselective LC analysis of synephrine in natural products on a protein-based chiral stationary phase. J. Pharm. Biomed. Anal. 37(5): 839-849.

Penzak, S.R., Jann, M.W., Cold, J.A., Hon, Y.Y., Desai, H.D., and Gurley, B.J. (2001). Seville (sour) orange juice: synephrine content and cardiovascular effects in normotensive adults. J. Clin. Pharmacol. 41(10): 1059-1063.

Preuss, H.G., DiFerdinando, D., Bagchi, M., and Bagchi, D. (2002). Citrus aurantium as a thermogenic, , weight-reduction replacement for ephedra, weight-reduction replacement for ephedra: an overview. J. Med. 33(1-4): 247-264.

Roman, M.C., Betz, J.M., and Hildreth, J. (2007). Determination of synephrine in bitter orange raw materials, extracts, and dietary supplements by liquid chromatography with ultraviolet detection: singlelaboratory validation. J. AOAC Int. 90(1): 68-81.

Rucker, D., Padwal, R., Li, S.K., Curioni, C., and Lau, D.C. (2007). Long term pharmacotherapy for obesity and overweight: updated meta-analysis. BMJ 335(7631): 1194-1199.

Sander, L.C., Putzbach, K., Nelson, B.C., Rimmer, C.A., Bedner, M., Thomas, J.B., Porter, B.J., Wood, L.J., Schantz, M.M., Murphy, K.E., Sharpless, K.E., Wise, S.A., Yen, J.H., Siitonen, P.H., Evans, R.L., Nguyen Pho, A., Roman, M.C., and Betz, J.M. (2008). Certification of standard reference materials containing bitter orange. Anal. Bioanal. Chem. 391(6): 2023-2034.

Shara, M., Stohs, S.J., and Mukattash, T.L. (2016). Cardiovascular safety of oral $p$-synephrine (bitter orange) in healthy subjects: a randomized placebo-controlled cross-over clinical trial. Phytother. Res. 30(5): 842-847.

Shiraishi, T., Onoe, M., Kojima, T.A., Kageyama, T., Sawatsugawa, S., Sakurai, K., Yoshimatsu, H., and Sakata, T. (2003). Effects of bilateral auricular acupuncture stimulation on body weight in healthy volunteers and mildly obese patients. Exp. Biol. Med. 228(10): 1201-1207.

Stohs, S.J. (2010). Assessment of the adverse event reports associated with Citrus aurantium (bitter orange) from April 2004 to October 2009. J. Funct. Foods 2(4): 235-238.

Stohs, S.J., Preuss, H.G., Keith, S.C., Keith, P.L., Miller, H., and Kaats, G.R. (2011). Effects of $p$-synephrine alone and in combination with selected bioflavonoids on resting metabolism, blood pressure, heart rate and self-reported mood changes. Int. J. Med. Sci. 8(4): 295.

Stohs, S.J., Preuss, H.G., and Shara, M. (2011). A review of the receptorbinding properties of $p$-synephrine as related to its pharmacological effects. Oxid. Med. Cell. Longev. 2011: 1-9.

Tainter, M.L., Cutting, W.C., and Stockton, A. (1934). Use of dinitrophenol in nutritional disorders: a critical survey of clinical results. Am. J. Public Health Nations Health. 24(10): 1045-1053.

Thielecke, F., and Boschmann, M. (2009). The potential role of green tea catechins in the prevention of the metabolic syndrome-a review. Phytochemistry. 70(1): 11-24.

Titta, L., Trinei, M., Stendardo, M., Berniakovich, I., Petroni, K., Tonelli, C., Riso, P., Porrini, M., Minucci, S., Pelicci, P.G., Rapisarda, P., Reforgiato Recupero, G., and Giorgio, M. (2010). Blood orange juice inhibits fat accumulation in mice. Int. J. Obesity. 34(3): 578.

Tsujita, T., and Takaku, T. (2007). Lipolysis induced by segment wall extract from Satsuma mandarin orange (Citrus unshu Mark). J. Nutr. Sci. Vitaminol. 53(6): 547-551.

Tung, Y.C., Chang, W.T., Li, S., Wu, J.C., Badmeav, V., Ho, C.T., and Pan, M.H. (2018). Citrus peel extracts attenuated obesity and modulated gut microbiota in mice with high-fat diet-induced obesity. Food Funct. 9: 3363-3373.

Uckoo, R.M., Jayaprakasha, G.K., Nelson, S.D., and Patil, B.S. (2011). Rapid simultaneous determination of amines and organic acids in citrus using high-performance liquid chromatography. Talanta. 83(3): 948954.

Westerterp-Plantenga, M., Diepvens, K., Joosen, A.M., Bérubé-Parent, S., and Tremblay, A. (2006). Metabolic effects of spices, teas, and caffeine. Physiol Behav. 89(1): 85-91.

Word Health Organization. (2018). Word Health Organization Obesity and overweight. http://www.who.int/news-room/fact-sheets/detail/ obesity-and-overweight. Accessed 12 Nov. 2018.

Wolfram, S., Wang, Y., and Thielecke, F. (2006). Anti-obesity effects of green tea: From bedside to bench. Mol Nutr Food Res. 50(2): 176187.

Yun, J.W. (2010). Possible anti-obesity therapeutics from nature-A review. phytochemistry. 71(14-15): 1625-1641.

Zang, L., Shimada, Y., Kawajiri, J., Tanaka, T., and Nishimura, N. (2014). Effects of Yuzu (Citrus junos Siebold ex Tanaka) peel on the diet-induced obesity in a zebrafish model. J. Funct. Food. 10: 499-510.

Zhong, M. (2010). TGR5 as a therapeutic target for treating obesity. Curr. Top. Med. Chem. 10(4): 386-396. 